\title{
Pengembangan Potensi Sumber Daya Manusia Melalui Teknologi Komunikasi Media Sosial di Era Milenial Desa Kampil
}

\author{
Fitri Wulan Ningsih ${ }^{1}$, Teddy Dyatmika ${ }^{2}$ \\ IAIN Pekalongan, Jl. Kusuma Bangsa No.9, Panjang Baru, Pekalongan Utara, Kota Pekalongan, Jawa \\ Tengah $51141^{1,2}$ \\ teddy.dyatmika@iainpekalongan.ac.id ${ }^{1 *}$
}

(Diajukan: 08 Juli 2021, Direvisi: 22 Juli 2021, Diterima: 01 Agustus 2021)

\begin{abstract}
ABSTRAK
Memasuki era transformasi digital ditahun 2021, perkembangan teknologi komunikasi terutama media sosial sudah sangat pesat dan tak terbatas. Dalam dunia yang semakin canggih ini dibeberapa daerah di Indonesia masih beberapa daerah yang belum dapat mengoptimalkan media sosial salah satunya di desa Kampil RT 06 RW02 Kecamatan Wiradesa. Ditengah perkembangan teknologi komunikasi saat ini pemuda Desa Kampil RT 06 RW 02 masih mengandalkan pekerjaan mereka sebagai buruh bangunan, petani, pedagang rumahan, dan juga merantau ke kota lain dengan pekerjaan serupa bahkan ada yang tidak memiliki pekerjaan. Hal tersebut tentu menjadi masalah yang harus diselesaikan, tertutama bagi kalangan pemuda agar kedepannya desa kampil RT 06 menjadi desa yang sejahtera di bidang ekonomi. Dalam penyelesaian masalah ini, metode yang digunakan adalah metode training atau pelatihan. Teknologi komunikasi terutama kehadiran media sosial yang ada ditengah masyarakat saat ini dapat menjadi jalan keluar dari masalah tersebut. Dalam memanfaatkan teknologi itu sendiri yang cenderung menguasai dalam penggunaan teknologi komunikasi biasanya adalah pemuda, untuk itu pemuda adalah sasaran dalam penyelesaian masalah ini. Pelatihan yang dialakukan adalah dengan pengenalan media sosial, pemanfaatan media sosial untuk promosi dan bagaimana optimalisasi media sosial dalam mempromosikan produk dan jasa. Dampak yang muncul dari pelatihan ini adalah pemuda lebih memahami fungsi media sosial dan dapat memanfaatkan media sosial untuk keperluan promosi.
\end{abstract}

\section{Kata Kunci: Pemuda, Pekerjaan, Media Sosial}

\begin{abstract}
Entering the digital transformation era in 2021, communication technology, especially social media, is very fast and unlimited. In this increasingly sophisticated world, in some areas in Indonesia, there are still some areas that have not been able to optimize one of the social media in Kampil village, RT 06 RW02, Wiradesa subdistrict. In the development of communication technology, the youth of Kampil Village RT 06 RW 02 still rely on their work as construction workers, farmers, home traders, and also migrate to other cities with similar jobs and some even do not have jobs. This is certainly a problem that must be resolved, especially for the youth so that in the future Kampil Village RT 06 becomes a prosperous village in the economic field. In solving this problem, the method used is the method of training or training. Communication technology, especially the presence of social media in today's society can be a way out of this problem. In utilizing the technology itself, those who master the use of communication technology are usually young people, for that youth are the targets in solving this problem. The training carried out is with the introduction of social media, the use of social media for and how to optimize social media in promoting products and services. The impact that emerged from this training was that young people better understood the function of social media and could use social media for promotional purposes.
\end{abstract}

Keywords: Youth, Work, Social Media

Pengembangan Potensi Sumber, (Fitri Wulan Ningsih)|313 


\section{PENDAHULUAN}

Perkembangan teknologi komunikasi di era transformasi digital saat ini, membawa perubahan yang sangat signifikan dalam kehidupan masyarakat seluruh dunia tak terkecuali Indonesia sebagai negara dengan tingkat kepadatan penduduk yang tinggi. Teknologi komunikasi merupakan sebuah sarana yang menghubungkan seseorang dengan orang lainnya melalui sebuah perangkat (Stiawan et al., 2020). Komunikasi itu bertujuan: megharapkan pengertian, dukungan gagasan dan tindakan. Setiap kali bermaksud mengadakan komunikasi perlu meneliti apa yang menjadi tujuan (Kharim, 2020). Teknologi komunikasi dapat merambat kesebagian besar wilayah Indonesia dengan mudah dan membantu pekerjaan manusia. Namun dibalik segala kemudahan yang dimiliki, diperlukan pengetahuan yang mumpuni juga dalam pengaplikasian dan pemanfaatannya. Artinya terjadi ketidakseimbangan antara semakin canggihnya teknologi saat ini dengan cara penggunaannya. Akibatnya masyarakat menjadi mudah terpengaruh berita berita HOAX dan gampang diprovokasi untuk menyebar kebencian. Keterampilan menggunakan teknologi komunikasi secara bijak tidak merata dan tidak sebanding dengan perkembangannya dibeberapa tempat atau wilayah seperti di desa Kampil RT 06 RW 02 kecamatan Wiradesa Kabupaten Pekalongan. Desa ini bukan desa pelosok yang sulit mendapatkan listrik ataupun internet. Perkembangan teknologi komunikasi yang ada di desa ini juga sama halnya seperti daerah-daerah sekitar seperti di perkotaan. Namun perkembangan teknologi komunikasi terutama media sosial yang ada ditengah masyarakat desa ini nyatanya tidak membawa pengaruh bagi kehidupan sosial khususnya pada bidang ekonomi. Padahal kehadiran media sosial harusnya bisa dioptimalisasikan sebagai media sarana promosi (Fantini et al., 2021). Sumber Daya Manusia (SDM) yang ada di Desa Kampil RT 06 RW 02 ini tidak terdorong dengan adanya kecanggihan teknologi saat ini. Masih banyak pemuda di Desa Kampil RT 06 RW 02 yang belum dapat mengoptimalisasikan dan memanfaatkan kehadiran media sosial untuk keperluan promosi produk ataupun jasa yang mereka miliki. Hal tersebut perlu ditindak lanjuti, agar para pemuda mampu membawa desa kampil RT 06 RW 02 ini menjadi desa yang lebih makmur dalam segi ekonomi melalui teknologi komunikasi.

Menanggapi masalah tersebut diperlukan kesadaran penuh dari seluruh lapisan masyarakat untuk membawa Desa Kampil RT 06 RW 02 menjadi desa yang lebih maju dalam pemanfaatan Sumber Daya Manusia melalui teknologi komunikasi sebagai penyelarasan 
dalam perkembangan zaman. Adapun solusi yang kami berikan adalah dengan memberikan pelatihan atau training kepada beberapa pemuda desa Kampil RT 06 RW 02. Pelatihan yang dimaksud adalah dengan memberikan pengarahan yang benar dalam pengaplikasian teknologi komunikasi dalam hal ini pemanfaatan media sosial. Seperti cara berkontribusi sebagai pengguna profesional di ranah online, cara memulai usaha kreatif melalui sumber sumber yang ada disitus belajar online, dan strategi yang harus dimiliki untuk dapat bersaing dengan para pelaku usaha online lain. Pemanfaatan media sosial untuk media promosi saat ini menjadi sesuatu hal yang penting apalagi di tengah pandemi (Junawan \& Laugu, 2020).

Output atau target luaran yang dihasilkan dalam permasalahan ini adalah para pemuda teredukasi dengan pelatihan yang dijalaninya sehingga timbul motivasi belajar untuk lebih giat dalam pemanfaatan teknologi komunikasi secara menyeluruh. Sehingga pola pekerjaan akan semakin berubah mengikuti perkembangan zaman dan Sumber Daya Manusia (SDM) dapat teroptimalisasi dengan kecanggihan teknologi komunikasi yang ada ditengah masyarakat saat ini. Hal tersebut juga akan membawa perubahan sosial masyarakat nantinya khususnya dalam bidang ekonomi. Masyarakat juga akan semakin bijak dalam menggunakan teknologi komunikasi sehingga meminimalisir terjadinya provokasi buruk ataupun berita HOAX.

\section{METODE}

Kegiatan pengembangan potensi Sumber Daya Manusia (SDM) melalui teknologi komunikasi khususnya bagi generasi milenial atau pemuda ini dilaksanakan pada 9 Juni 2021 dan bertempat di Desa Kampil Dukuh Sasem Kecamatan Wiradesa Kabupaten Pekalongan. Mayoritas peserta yang mengikuti kegiatan ini berusia 15 sampai 18 tahun dan pemuda asli desa Kampil. Total peserta yang mengikuti kegiatan ini merupakan pelajar aktif dan mampu menggunakan ponsel atau alat komunikasi secara baik. Akan tetapi, mereka bulum sanggup mengoptimalkan peralatan teknologi yang mereka miliki. Teknologi komunikasi yang mereka punya hanya digunakan untuk hal-hal pokok seperti sekolah daring ataupun memainkan ponsel untuk hiburan saja seperti bermain media sosial. Ini senada dengan penelitian yang dilakukan oleh we are social dan hootsuite yang menyatakan bahwa 170 juta masyarakat Indonesia menggunakan media sosial (Stephanie, 2021). Ini senada dengan penelitian yang sudah dilakukan, bahwa kemampuan siswa dan mahasiswa dalam menggunakan internet 
sebenarnya sudah dalam taraf yang baik. Akan tetapi, jika tidak diarahkan untuk hal-hal yang positif bisa berbahaya (Dyatmika et al., 2021).

Melihat kondisi yang ada di lokasi metode yang menurut kami paling efisien digunakan adalah training atau pelatihan. Karena metode ini menekankan pada pemahaman individu mengenai masalah yang akan dibahas dan lebih memberikan pemahaman yang mendalam juga karena peserta langsung diberikan arahan mengenai cara menggunakan teknologi dalam bidang ekonomi. Materi yang disampaikan kepada peserta meliputi cara berkontribusi sebagai pengguna profesional di ranah online, cara memulai usaha kreatif melalui sumber sumber yang ada disitus belajar online, dan strategi yang harus dimiliki untuk dapat bersaing dengan para pelaku usaha online lain.

\section{HASIL, PEMBAHASAN, DAN DAMPAK}

Teknologi komunikasi merupakan alat penghubung antara satu individu dengan individu lain untuk saling berbagi informasi mengenai perkembangan yang ada saat ini. Kemudahan yang dimiliki oleh teknologi komunikasi diharapkan mampu menunjang Sumber Daya Manusia sehingga kehidupan masyarakat menjadi lebih baik terutama dalam segi ekonomi. Mayoritas masyarakat yang aktif dalam menggunakan teknologi komunikasi adalah generasi milenial. Hal inilah yang menjadikan generasi milenial Desa Kampil sebagai sasaran utama dalam penyelesaian permasalahan pengembangan potensi Sumber Daya Manusia melalui teknologi komunikasi di Desa Kampil.

Setelah diadakannya training atau pelatihan pada 9 Juni 2021 dengan beberapa pertanyaan yang kami ajukan mengenai pemahaman mereka mengenai teknologi komunikasi. Wawasan mereka hanya sampai pada hiburan dan sebagai alat untuk sekolah atau perkuliahan daring saat ini. Adapun keterampilan yang mereka miliki dalam penggunaan ponsel belum mampu menunjang Sumber Daya Manusia yang perlu diasah mulai dari sekarang.

Senada dengan apa yang disampaikan oleh (Astuti \& Nurmalita, 2014) harus diakui, di jaman sekarang manusia mau tidak mau harus mengikuti perkembangan yang telah ada. Jika tidak, mereka juga akan ketinggalan informasi dan mungkin juga akan terkucilkan atau teralienasi oleh keadaan. Dari inilah kami termotivasi untuk setidaknya memberikan sedikit training atau pelatihan kepada generasi milenial desa Kampil agar tidak tertinggal dengan perkembangan zaman. 
Proses pelatihan yang kami lakukan kepada para peserta dimulai dengan menanyakan kepada mereka mengenai pemahaman tentang kegunaan teknologi, apa saja kesulitan dalam mengasah kemampuan sumber daya manusia (SDM) sesuai dengan bakat dan minat yang mereka miliki, dan motivasi mereka dalam jangka waktu 5-10 tahun kedepan. Setelah menganalisa permasalahan yang ada, kami memberikan pemahaman mengenai teknologi komunikasi itu sendiri, hal hal yang perlu dilakukan dalam memulai pengembangan potensi Sumber Daya Manusia yang mereka miliki seperti menganalisa atau mempelajari lebih dulu dunia online, memulai usaha kreatif dengan dasar pengetahuan yang mereka miliki ditambah dengan sumber atau referensi yang mereka dapat dari teknologi komunikasi, dan strategi yang tepat dalam persaingan di media teknologi komunikasi itu sendiri. Selain melalui penyampaian materi, saya juga memaparkan video berdurai kurang lebih 5 menit yang berisi motivasi memulai bisnis online.

Setelah pelatihan berupa penyampaian materi dan pemaparan video selesai disampaikan. Para peserta mulai teredukasi dengan pentingnya mengembangkan potensi diri dengan teknologi saat ini agar tidak tertinggal dengan zaman dan Sumber Daya Manusia yang mereka miliki dapat teroptimalisasi. Peserta memulai pengembangan potensi mereka dengan berjualan di situ belanja online dan membuat kerajinan tangan berupa anyaman dan di explore melalui aplikasi seperti instagram, facebook, dan telegram. Beberapa hal yang menjadi pedorong dalam pelaksanaan pelatihan ini adalah partisipasi peserta dalam mengikuti kegiatan dari awal hingga akhir, para peserta pun aktif dalam kegiatan tanya jawab dan sharing pengalamannya ketika melihat atau mencoba berkontribusi dalam perkembangan potensi diri melalui teknologi komunikasi. Melaui media sosial juga mereka dapat mengetahui perkembangan anyaman yang sedang diminati masyarakat seperti apa. Hal tersebut dikarenakan media sosial juga dapat memberikan pengetahuan kepada masyarakat (Vinka \& Michele, 2021). Faktor pendorong lain adalah ketersediaan tempat dan fasilitas lain seperti papan tulis, dan alat tulis.

Kendala dalam proses pelatihan sendiri adalah keterbatasan waktu sehingga dalam beberapa point tidak dijabarkan secara terperinci dan hanya fokus pada solusi yang relevan pada kondisi aslinya. Kendala lain yang menjadi penghambat dalam pelatihan ini adalah training atau pelatihan yang terkesan membosankan. Sehingga harus di selingi dengan bertukar cerita atau pengalaman dan menjadikan suasana pelatihan menjadi menyenangkan karena diselingi dengan aktivitas lain. 

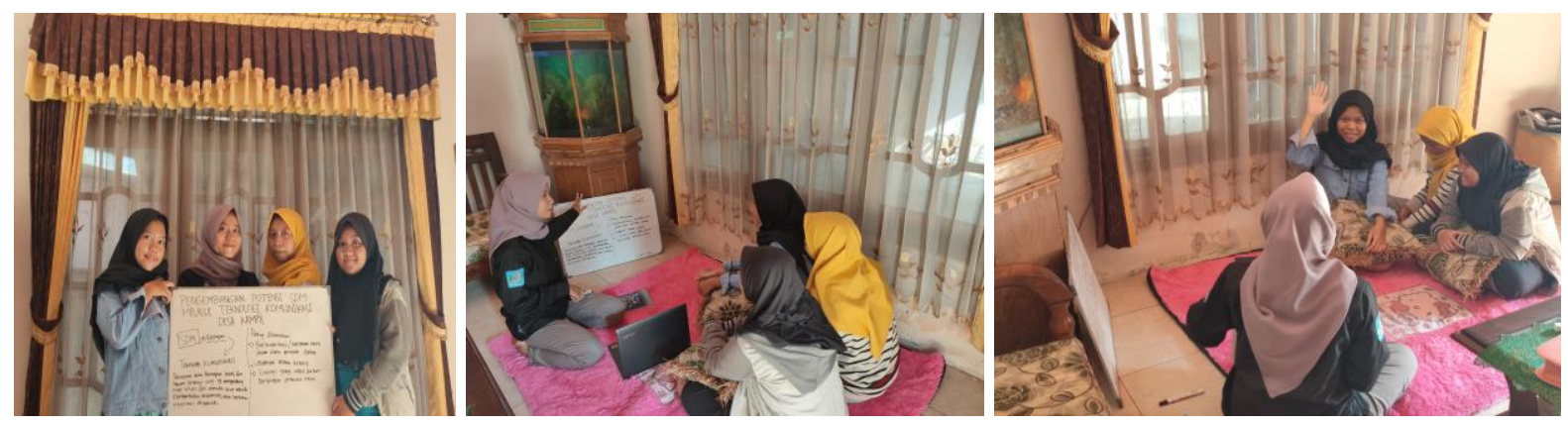

Gambar 1. Proses Pelaksanaan Pemberian Edukasi

Setelah dilakukan pelatihan ada dampak yang cukup signifikan. Sebelumnya pemuda Desa Kampil RT 06 RW 02 yang mengikuti pelatihan, sebagian besar belum meiliki kemampuan untuk memanfaatkan media sosial untuk keperluan promosi. Ada beberapa produk yang mereka jual misalnya anyaman. Penjualan memang menggunakan media sosial seperti facebook atau instagram. Akan tetapi sedikitnya jumlah follower membuat penjualan melalui media sosial jalan di tempat. Dalam pelatihan yang dilakukan salah satunya dengan optimalisasi media sosial yaitu bagaimana cara menambahkan jumlah follower, bagaimana membuat caption (narasi) yang menarik dan kapan sebaiknya postingan dilakukan. Setelah melakukan pelatihan dampak yang muncul cukup bagus. Ada peningkatan pengetahuan dari yang awalnya tidak mengetahui cara menaikkan follower sekarang sudah mengetahuinya. Pada awalnya belum bisa membuat caption yang menarik sekarang sudah bisa mereka lakukan untuk menarik konsumen. Selain itu pemuda Desa Kampil RT 06 RW 02 sekarng juga memiliki pengetahuan kapan harus posting produk mereka secara teratur tidak asalasalan.

\section{SIMPULAN}

Pelatihan yang dilakukan kepada pemuda Desa Kampil RT 06 RW 02 sangat efektif, terutama dalam memberikan pengetahuan mereka. Pengetahuan disini adalah pengetahuan mengenai teknologi komunikasi atau lebih tepatnya pemanfaatan media sosial sebagai media promosi produk untuk meningkatkan perekonomian masyarakat terutama pemuda Desa Kampil RT 06 RW 02. Hasil dari pengadian ini memberikan dampak yang signifikan. Pemuda yang awalnya tidak begitu paham memanfaatkan media sosial sebagai media promosi, setelah pelatihan menjadi lebih menguasai. Mereka jadi mengetahui bagaimana melakukan promosi produk maupun jasa dengan baik. Para pemuda juga sekarang mengetahui bagaimana cara 
meningkatkan jumlah follower, bagaimana membuat caption yang menarik dan kapan waktu yang tepat memposting produk mereka di media sosial. Saran setelah melakukan pengabdian ini adalah perlu adanya komunitas yang saling mendukung agar semangat untuk terus menjadi wirausaha tetap tumbuh dan juga bisa menyebar keseluruh warga (Mikke Setiawati \& Makkuraga Putra, 2021). Melalui komunitas bisa saling support terutama dalam mempromosikan produk mereka.

\section{UCAPAN TERIMAKASIH}

Penulis mengucapkan terimakasih kepada para peserta yang ikut berpartisipasi dalam pelatihan ini, dan kepada seluruh warga Desa Kampil Dukuh Sasem Kecamatan Wiradesa Kabupaten Pekalongan.

\section{DAFTAR PUSTAKA}

Astuti, A. P., \& Nurmalita, A. (2014). Teknologi Komunikasi dan Perilaku Remaja. Jurnal Analisa Sosiologi, 3(1), 91-111.

Dyatmika, T., Bakhri, S., \& Kamal, M. R. (2021). Hoax dan Literasi Media Internet di Era Covid-19. Sangkep, 4(1), 64-93. https://doi.org/10.20414/sangkep.v2i2.p-ISSN

Fantini, E., Sofyan, M., \& Suryana, A. (2021). Optimalisasi Sosial Media Sebagai Sarana Promosi Usaha Kecil Menengah Meningkatkan Penjualan di Masa Pandemi Covid-19. Jurnal Ekonomi, Manajemen, Bisnis Dan Sosial, 1(2), 126-131. https://doi.org/10.5281/ZENODO.4575272

Junawan, H., \& Laugu, N. (2020). Eksistensi Media Sosial, Youtube, Instagram dan Whatsapp Ditengah Pandemi Covid-19 Dikalangan Masyarakat Virtual Indonesia. Baitul 'Ulum: Jurnal Ilmu Perpustakaan Dan Informasi, 4(1), 41-57. https://doi.org/10.30631/baitululum.v4i1.46

Kharim, A. (2020). Dakwah Dan Tantangannya Dalam Media Teknologi Komunikasi. 69-90. https://doi.org/10.31219/osf.io/pxzrv

Mikke Setiawati, \& Makkuraga Putra, A. (2021). Pola Komunikasi Komunitas di Media Sosial Dalam Menciptakan Minat Entepreneur. Communications, 3(1), 43-57. https://doi.org/10.21009/communications.4.1.3

Stephanie, C. (2021). Riset Ungkap Lebih dari Separuh Penduduk Indonesia “Melek” Media Sosial. https://tekno.kompas.com/read/2021/02/24/08050027/riset-ungkap-lebih-dariseparuh-penduduk-indonesia-melek-media-sosial

Stiawan, A., Baharuddin, H., \& Amrozi, Y. (2020). Masa Depan Teknologi Komunikasi Data 
, Menebak Arah Perkembangannya. INTEGRER: Journal of Information Technology, $5(2), 1-5$.

Vinka, A. M., \& Michele, N. (2021). Pengaruh Teknologi Internet Terhadap Pengetahuan Masyarakat Jakarta Seputar Informasi Vaksinasi Covid-19. Jurnal Teknologi Informasi Dan Komunikasi, 8(1), 1-13. 